\title{
The Effect of 8 Weeks Aerobic Training on Angiogenesis (VEGF) and Angiostatic (ES) Factors In Sedentary Women
}

\author{
Javad Tolouei Azar', Aliasghar Ravasi', Rahman Soori", Ali Akbarnejad ', Mohammad Hemati Nafar ${ }^{\star}$
}

Received 10 Nov, 2016, accepted for publication 17 Jan, 2017

\begin{abstract}
Background \& Aims: It is more important to know which of physical activities could be the most effective way to cause angiogenesis. In this regards, we have investigated an 8-week aerobic training on vascular endothelial growth factor (VEGF) and Endostatin (ES) in sedentary women.

Materials \& Methods: 20 volunteer inactive women were chosen and were randomly divided in 2 groups of aerobic and control. Aerobic training programme consisted of 3 days per week for 8 weeks, each consists of 30 minutes with intensity of $65-70 \%$ of maximum heart rate was performed.. Before and after training, we have tested aerobic training and control group after an overnight fast. Blood Samples were used to conduct Enzyme-linked immunosorbent assay (ELISA). Independent and Dependent T-Test t were performed to see the significance level of $(\mathrm{P}<0.05$.

Results: Statistical analysis revealed that aerobic training increased VEGF and decreased ES to a significant level. Consequently, the results of Independent $\mathrm{T}$ Test revealed that there is an obvious difference $(\mathrm{P}<0.05)$, between the amount of VEGF and ES in control and intervention group.

Conclusion:The results show that the equilibrium between angiogenesis and angiostatic agents. As a result, aerobic training is shifted toward angiogenesis factors. This result helps us to understand the process of angiogenesis consistence with aerobic training activities.
\end{abstract} KeyWords: Aerobic training, Angiogenesis, VEGF, ES, Sedentary women

Address: Faculty of Physical Education and Sport Sciences, Urmia University, Urmia, Iran

Tel: (+98) 9143410949

Email: j.tolouei@gmail.com

\section{Introduction}

Sport activities have an important influence on factors which cause cardiovascular diseases. These activities improve the general density of lipoprotein, general fat content (1), insulin sensitivity to, glucose release and glucose tolerance(2). Also, sport activities control blood pressure in individuals on the verge of high blood pressure(3). Aerobic exercises decrease blood pressure and heart beat. Aerobic exercises increase V02 max and aerobic enzymes activity and extend capillary network in heart and skeletal muscles(4). The extension of this network is done through arteriogenesis and angiogenesis processes on the

\footnotetext{
${ }^{1}$ Assistant professor of exercise physiology, Urmia University, Urmia, Iran. (Corresponding Author)

2 Professor of exercise physiology, University of Tehran, Tehran, Iran.

${ }^{3}$ Associate Professor of exercise physiology, University of Tehran, Tehran, Iran.

${ }^{4}$ Associate Professor of exercise physiology, University of Tehran, Tehran, Iran.

${ }^{5}$ Assistant professor of exercise physiology, Shiraz University, Shiraz, Iran.
} 
vascular bed of skeletal muscle which decrease or omit the stress caused by sport act in ties(5). Arteriogenesis refers to an increase in the diameter of existing arterial vessels (6). However, Angiogenesis means the formation of new capillaries from the previous capillary(7). In angiogenesis process, endothelium acts differently in reaction to different stress incentives because of angiogenic factors (vessel-make factors) and angiostatic factors (controlling factors)(8).

Angiogenic factors are those factors involved in the formation of new capillaries either directly or indirectly and help making and evolving of vessels. The lack of any of these factors disturbs the stages in making and evolving capillaries(9). The most important growth factor in angiogenesis process is vascular endothelial growth factor (VEGF)(10). The 45-kDa glycoprotein factor provides necessary ground for the survival, multiplication, immigration, and penetrability of cardiovascular endothelial vessel through increasing adjustment of anti-apoptotic components, DNA synthesis, destruction of basic membrane and phosphorylation of intercellular adhesion molecules and finally causes the formation of new vessels (11).

On the other hands, angiostatic factors are factors which enter the angiogenic process in a certain stage and hamper it. Endostatin (ES) is a 20-KDa part which is released from the terminal C of XVIII collagen and inhibits angiogenesis. In its prevention mechanism, endostatin connects to a VEGF angiogenic factor and prevents it for function and in this way Inhibits endothelial cell proliferation. Also, endostatin prevents the destruction of the vessel's basic membrane which eventually prevents endothelial cells from immigration. In fact, endostatin prevents the multiplication and immigration of endothelial cells and by doing so prevents the growth of capillary network(12).

In normal situations, there is a balance between angiogenic and angiostatic factors. However, this balance is always disturbed in physiological and pathological situations and one of these situations is exercise(13).

The effect of exercise on serum amounts of angiogenic factors leads to contradictory results. As Ravasi et al (2014) showed in their study of the effect of two kinds of physical activities (one session of progressive aerobic activity and one intensive interval) on the serum response of VEGE on non athlete men. These two factors can change the levels of VEGF angiogenic factor with the same degree(14). Nourshahi et al (2013) studied the effect of six-week resistance training on VEGF and endostatin on tumor texture in rats inflicted with breast cancer and showed that these training have no effect on the angiogenesis pattern of tumor texture and its growth(15). Rojas et al (2010) studied the effect of high intensity resistance exercise (knee extension) on serum amount of VEGF and insulin-like growth factor and concluded that serum IGF-1 was increased after exercise while serum levels of VEGF remain the same(16). Gavin et al (2007), in a study entitled "acute resistance exercise increases skeletal muscle angiogenic growth factor expression" asked participants to do resistance training in the form of knee extension for three times with 10 repetitions, each time with 60 to 80 percent 1RM. Blood and muscle samples were taken from them before and after the activity. The results showed that exercise increased the mRNA and VEGF protein in skeletal muscle(10). Nourshahi et al (2012) investigated the effect of six weeks of endurance training on the amount of VEGF and endostatin of tumor texture in rats inflicted with breast cancer and showed that 
enduramce training increases VEGF significantly but the increase of endostatin was not significant(17). Shekarchizadeh et al (2012) in their study of the effect of 4 weeks (3 days a week) of resistance training on the plasma level of nitric oxide, endothelial growth factor and its type-one receptor in male rats, showed that resistance training have no effect on the plasma level of effective factors on angiogenesis including NO and VEGF in healthy animals(18). Also, Ranjbar et al (2011) in their study of the effect of gender and physical activity on serum vascular endothelial growth factor at rest and response to submaximal exercise, showed that gender and the amount of physical activity aren't among the effective factors on the amount of VEGF while resting and in response to endurance activities(19). Our investigations show that studies about the effect of long term exercise on angiogenesis factors are rare and most studies have focused on short and onesession exercise. It should also be mentioned that in the investigated researches, both angiogenic (VEGF) and angiostatic (ES) factors have not been studied simultaneously and in the form of an aerobic training plan. Thus, this study sets to answer the effect of 8 weeks aerobic training on VEGF and ES in sedentary women.

\section{Materials and Methods}

The present study is a pre-test - post-test quasiexperimental test with a control group. The population of this study was sedentary women from Urmia with ages 30-40. The inclusion criteria were as follows: not having medical record, not taking the medicine while taking part in the research, not having a regular sport record (at least six months before the research). The exclusion criteria were: not being interested in the research, taking medicine and nutritional supplements, not participating in the session regularly, and injury. In this study, from the initial 60 sedentary women, 20 with ages 30-40 were randomly selected after filling out the satisfaction form and health questionnaire. These women were categorized into two equal groups of aerobic exercise and control.

\section{Measuring the demographic variables:}

These variables include age (years old), height $(\mathrm{cm} /$ with meter), weight ( $\mathrm{kg} /$ with digital weight), and BMI (dividing weight by the square of height). Omron (Omron BF306 Body Composition Monitor) made in Korea was used to measure the percentage of body fat. Participants, while standing, grabbed the sensors with both hands. Then, start button was pressed and body fat was measured.

\section{Training plan:}

In the briefing session, the way of doing training and the research time schedule were explained to the participants. Then, they were ready to take part in the training plan.

\section{- Aerobic training}

Participants did 8 weeks of training on the treadmill for 3 times per week, each time 30 minutes, with intensity of $65-70 \%$ of Maximum heart rate (age220). To control the intensity of exercise, heart rate monitor was used. Each training session included:

10 minutes stretching and active warm-up, 30 minutes aerobic training on the treadmill, and final 5 minutes cool-down and recovery (Table 1).

\section{- The intensity of the aerobic training}

The participants in the aerobic training group did activities before the main training with the intensity of 50-60\% maximum heart rate to gradually adapt to the real pressure of the activity. Then, the real training began in 65 to $70 \%$ maximum heart rate. While doing the aerobic training and if the increase or decrease of intensity was required, the necessary feedback was given to the participants (Table 1). 
$\underline{\text { Table 1. Intensity and duration of aerobic training ( } 3 \text { sessions per week) }}$

\begin{tabular}{|c|c|c|c|c|c|c|c|c|}
\hline & $1^{\text {st }}$ week & $2^{\text {nd }}$ week & $3^{\text {rd }}$ week & $4^{\text {th }}$ week & $5^{\text {th }}$ week & $6^{\text {th }}$ week & $7^{\text {th }}$ week & $8^{\text {th }}$ week \\
\hline $\begin{array}{l}\text { Intensity } \\
\text { (MHR) }\end{array}$ & $50 \%$ & $55 \%$ & $60 \%$ & $65 \%$ & $70 \%$ & $70 \%$ & $70 \%$ & $70 \%$ \\
\hline $\begin{array}{l}\text { Time } \\
\text { (Min) }\end{array}$ & 30 & 30 & 30 & 30 & 30 & 30 & 30 & 30 \\
\hline
\end{tabular}

\section{- Control group}

The participants in this group had no regular sport activity and their physical activity was controlled based on their own reports.

\section{Blood sampling:}

Blood sampling was done after 12 hours of fasting in two stages. In the first stage, based on the guidelines for blood sampling conditions, participants were asked to avoid doing any intense physical activity, stressful situations, and taking medicine for 3 days before sampling. The resulted serums were frozen in -70 centigrade. The second time of blood sampling was done 48 hours after the last training session. VEGF and ES were measured by the enzyme-linked immunosorbent assay (ELISA) with a special kit.

\section{Statistical method:}

Descriptive statistics were used to analyze the research data for measuring the central indexes and dispersion. The K-S test was used to identify the normal distribution of data. The Leven test was used to determine the homogeneity of variances. The Paired $\mathrm{T}$ test was used to investigate the changes from pre-test to post-test. The independent $\mathrm{T}$ test was used to investigate the changes between groups. Data were analyzed using SPSS version 21 and the level of significance was $\mathrm{p}<0.05$.

\section{Results}

Physical and physiological traits of the participants are shown in Table 2.

Table 2. Physical and physiological traits of the participants, before and after 8 weeks of training

\begin{tabular}{lllll} 
Group & Aerobic training & & Control \\
\hline Variable & Pre-test & Post-test & Pre-test & Post-test \\
\hline Age (years) & $* 34.5 \pm 3.5$ & & $35.5 \pm 3.4$ & \\
Height (cm) & $167.5 \pm 5.02$ & & $165.7 \pm 5.14$ & $65.7 \pm 4.79$ \\
Weight (kg) & $65.9 \pm 4.2$ & $61.45 \pm 4.03$ & $65.6 \pm 4.69$ & $23.95 \pm 0.84$ \\
BMI (kg/m $\left.\mathbf{m}^{2}\right)$ & $23.6 \pm 0.82$ & $22.05 \pm 0.48$ & $23.89 \pm 0.86$ & $32.18 \pm 4.28$ \\
\hline Fat $(\%)$ & $32.98 \pm 4.04$ & $30.4 \pm 4.15$ & $32.01 \pm 4.22$ & \\
\hline
\end{tabular}

* The amounts are indicated as standard deviation \pm average.

The average and standard deviation of dependent variables, before and after 8 weeks of training, and the results of the paired $\mathrm{T}$ test and the independent $\mathrm{T}$ test are shown in Table 3.
The results of the paired $\mathrm{T}$ test showed that 8 weeks of aerobic training change the VEGF $(\mathrm{P}=0.001)$ and ES $(\mathrm{P}=0.001)$ in sedentary women while no significant difference was observed in the control group ( $P \geq 0.05)$. Also, the result of independent $T$ 
test showed that in the amount of VEGF and ES,

there is a significant difference between aerobic

and control groups (Table 3).

Table 3. The results of paired and independent $T$ tests in determining the difference between the research variables.

\begin{tabular}{|c|c|c|c|c|}
\hline \multirow{2}{*}{ Variable } & \multicolumn{3}{|l|}{ Group } & \multirow[t]{2}{*}{$\begin{array}{l}\text { Level } \\
\text { significance }\end{array}$} \\
\hline & & Aerobic training & Control & \\
\hline \multirow{4}{*}{ VEGF (ng/l) } & Pre-test & $134.9 \pm 28.67$ & $128.37 \pm 28.58$ & \\
\hline & Post-test & $215.6 \pm 43.39$ & $128.97 \pm 36.95$ & \\
\hline & Level of significance & \# 0.001 & 0.871 & \\
\hline & $\begin{array}{l}\text { The difference } \\
\text { Between pre and post }\end{array}$ & $80.7 \pm 14.72$ & $0.6 \pm 8.37$ & ${ }^{*} 0.001$ \\
\hline \multirow{4}{*}{ ES (ng/ml) } & Pre-test & $11.11 \pm 3.04$ & $10.82 \pm 2.45$ & \\
\hline & Post-test & $8.58 \pm 1.84$ & $10.72 \pm 2.40$ & \\
\hline & Level of significance & \# 0.001 & 1.0 & \\
\hline & $\begin{array}{l}\text { The difference } \\
\text { Between pre and post }\end{array}$ & $2.53 \pm 1.2$ & $0.1 \pm 0.05$ & ${ }^{*} 0.031$ \\
\hline
\end{tabular}

\# Significance as compared to pre-test amounts

* Significance as compared to aerobic group. The amounts are indicated as standard deviation \pm average.

\section{Discussion and Conclusion}

Blood vessels and capillaries provide oxygen and food for metabolic tissues and remove burn waste and thus have a crucial role in body function and health. In normal conditions, there is a balance between angiogenic and angiostatic factors. However, in Physiological and pathological situations, this balance is disturbed and one of these conditions is exercise(13).

It is shown that VEGF plays a crucial role in angiogenesis resulted from the exercise. This glycoprotein factor provides the necessary ground for the survival, multiplication, immigration, and penetrability of endothelial cell through the increasing adjustment of anti-apoptotic components, DNA synthesis, destruction of basic membrane and phosphorylation of sticky endothelial inter-vessel components and finally cause the formation of new vessels(11). In the present study, 8 weeks of aerobic training increased VEGF in sedentary women significantly. Also, there was a significant difference between the aerobic training and control groups. The increasing trend shows that VEGF and its receptors VEGFR1 and VEGFR2 and NPR-1 increased in response to a sport activity (20-21)

Long term sport training with moderate intensity is regarded as the positive regulator of VEGF mRNA expression and the protein content. For instance, Gavin et al (2004) showed that 60 minutes of cycling with the intensity of $50 \% \quad \mathrm{VO}_{2} \max$ increases VEGF around 4.5 times (22). Hoier et al 
(2012) showed that 60 minutes of cycling with the intensity of $60 \% \mathrm{VO}_{2}$ max leads increase in intertissue density 6 folds compared to the resting conditions (23). On the other hand, Brixius et al (2008) showed long term aerobic training in both groups (60 minutes running and 90 minutes cycling with the average intensity for six months, three times a week) doesn't lead to the change of VEGF level in the obese(24).

Different factors affect the production rate of VEGF as a result of exercise. Among these factors, hypoxia, shear stress (hemodynamic force as a result of the friction between blood flow and vessel wall), contraction and stretching of the muscle and disturbance of metabolism are the most important ones (25-26). Exercise leads to the higher speed of the blood circulation in the active muscle. Aerobic training increases blood circulation 5-6 folds(27). It seems that aerobic training increases Interstitial Calciumions (CaN and CaMK)(28), NO (eNOS and nNOS) (29) and hypoxia (HIF-1) and thus sets the $\operatorname{VEGF}(30)$.

The reason for the increase in VEGF in the present study is most probably was due to the decrease of ES. ES which prevents the increase in VEGF (31) by the induction of apoptosis in endothelial cells(32), prevents the immigration of endothelial cells(31), and suppressing the messaging of Nitric oxide(33).

Local discharge of cathepsins and extracellular matrix metalloproteinases (MMPs) through motivated endothelial cells leads to the release from XVIII collagen, prevention of angiogenesis, and decrease in the release of cathepsins and $\operatorname{MMPs}(12)$. In the present study, 8 weeks of aerobic training decreased ES in sedentary women significantly. Also, there was a significant difference between aerobic and control groups. Little information is available about the response of ES to exercise. In this regard, Rullman et al (2007) showed a single bout of exercise, 65 minutes of cycling with $65 \%$ $\mathrm{VO}_{2}$ max increases artery plasma endostatin 1.7 times in 17 minutes of exercise which is higher than the vein plasma ES (1.6 times). However, in 57 minutes of exercise it gets to the resting amounts and stays in the basic amounts until 120 minutes. It is interesting that vein plasma ES had a two-fold increase in 57 minutes of exercise which is significantly high in comparison with artery plasma ES. This suggests that absorption has occurred from blood circulation to muscle (34).

Also, it is shown that long term exercise like the one in this study can increase angiogenesis through decreasing endostatin. Brixius et al (2008) showed that long term aerobic exercise in both groups (60 minutes running and 90 minutes cycling with the medium intensity for 6 months, 3 times a week) decreases basic amounts of endostatin $14 \%$. Also, endostatin was decreased in both training groups as compared to the control group (24). Nourshahiet al (2012) investigated the effect of six weeks of endurance training on the amount of VEGF and endostatin of tumor tissue in rats inflicted with breast cancer and showed that endurance training increases VEGF significantly but the change in endostatin was not significant(17).

It seems that aerobic training in the present study increases angiogenesis through decreasing ES, because endostatin decreases angiogenesis by preventing the multiplication and immigration of endothelial cells (31), preventing the activity of angiogenesis inducers (such as VEGF and FGF2)(35), disturbing the activity of eNOS and decreasing the release of NO resulted from VEGF(33), preventing cyclin D1 (stopping G1 of cell cycle and apoptosis)(32), and preventing the activity of extracellular matrix metalloproteinases (MMP-2, MMP-9 and MMP-13)(36). However, the decrease in ES in response to the exercise is not 
clear yet. It is probable, though, that exercise decreases the change in extracellular matrix and this can lead to the prevention of the release of endostatin from collagen(37).

In short, the results showed that VEGF increases and ES decrease as a result of adapting to the aerobic training. These findings show that aerobic training changes the balance between angiogenic and angiostatic factors toward angiogenic factors.

Lack of control over the excitements and other mental factors in participants, as well as their sleep and resting conditions, were among the limitations of the present study. Also, since ES was decreased significantly in this study, and this was not observed in previous studies, interpreting and applying the findings to other studies create some limitations.

Since the increase in angiogenesis has a positive effect on people's health, this study suggests that individuals make use of aerobic training for motivating angiogenesis and improving their health.

\section{Acknowledgement}

Authors feel obliged to thank all the women taking part in the study. We are also grateful to the Laboratory of Pathobiology center of Urmia.

\section{References}

1. Dufaux B, Assmann G, Hollmann W. Plasma lipoproteins and physical activity: a review. Int $\mathrm{J}$ Sports Med 1982;3(3): 123-36.

2. Helmrich SP, Ragland DR, Leung RW, Paffenbarger Jr RS. Physical activity and reduced occurrence of non-insulin-dependent diabetes mellitus. $\mathrm{N}$ Engl $\mathrm{J}$ Med 1991;325(3): 147-52.

3. Fagard R. Exercise is good for your blood pressure: effects of endurance training and resistance training. Clin Exp Pharmacol Physiol2006;33(9): 853-6.
4. Tang K, Xia FC, Wagner PD, Breen EC. Exerciseinduced VEGF transcriptional activation in brain, lung and skeletal muscle. Respir Physiol Neurobiol 2010;170(1): 16-22.

5. Suhr F, Brixius K, de Marées M, Bölck B, Kleinöder $\mathrm{H}$, Achtzehn S, et al. Effects of short-term vibration and hypoxia during high-intensity cycling exercise on circulating levels of angiogenic regulators in humans. J Appl Physiol (1985) 2007;103(2): 474-83.

6. Brown M, Hudlicka O. Modulation of physiological angiogenesis in skeletal muscle by mechanical forces: involvement of VEGF and metalloproteinases. Angiogenesis 2003;6(1): 1-14.

7. Richardson R, Wagner H, Mudaliar S, Saucedo E, Henry R, Wagner P. Exercise adaptation attenuates VEGF gene expression in human skeletal muscle. Am J Physiol Heart Circ Physiol 2000;279(2): H772-H8.

8. Felmeden D, Blann A, Lip G. Angiogenesis: basic pathophysiology and implications for disease. Eur Heart J 2003;24(7): 586-603.

9. Huber-Abel FA, Gerber M, Hoppeler H, Baum O. Exercise-induced angiogenesis correlates with the upregulated expression of neuronal nitric oxide synthase (nNOS) in human skeletal muscle. European J Appl Physiol (1985) 2012;112(1): 155-62.

10. Gavin T, Drew J, Kubik C, Pofahl W, Hickner R. Acute resistance exercise increases skeletal muscle angiogenic growth factor expression. Acta Physiol 2007;191(2): 139-46.

11. Zachary I, Gliki G. Signaling transduction mechanisms mediating biological actions of the vascular endothelial growth factor family. Cardiovasc Res 2001;49(3): 568-81.

12. Ranjit Pm, Anuradha C, Vishnupriya S, Girijasankar G, Girish K, Chowdary Y. Endogenous Angiogenesis Inhibitor Endostatin: An Overview. Liver 2012;13: 14.

13. Bloor CM. Angiogenesis during exercise and training. Angiogenesis 2005;8(3): 263-71. 
14. Ravasi AA, Yadegari M, Choobineh S. Comparison of two types of physical activity on response serum VEGF-A, non-athletic men. J Sport Biosciences 2014;6(1): 41-56.

15. Nourshahi M. BA, Bigdeli M. R.,Ghasemi B. M.. The Effect of Six Weeks of Resistance Training on Tumor Tissue VEGF and Endostatin in Mice with Breast Cancer. J Sport Biosciences 2013;5(2): 27-46.

16. Rojas Vega S, Knicker A, Hollmann W, Bloch W, Strüder HK. Effect of resistance exercise on serum levels of growth factors in humans. Horm Metab Res 2010;42(13):982-6.

17. Nourshahi Maryam., Ghasemi B. M., Ayyub B., Zoheyr H., F. S. Effect of Six Weeks Continuous Aerobic Training on Tumoral Tissue Expression of Vascular Endothelial Growth Factor (VEGF) and Endostatin in Mice with Breast Cancer. J Tabriz Univ Med Sci 2012;34(6): 82-9.

18. Shekarchizadeh P, Khazaei M, Gharakhanlou R, Karimian J. The Effects of Resistance Training on Plasma Angiogenic Factors in Normal Rats. J Isfahan Med School 2012;30(176): 1-9.

19. Ranjbar K., Nourshahi M., Hedayati M ,.H. TC. Effect of Gender and Physical Activity on Serum Vascular Endothelial Growth Factor at Rest and Response to Submaximal Exercise. Iran J Endocrinol Metab 2011; 13(3): 294-300.

20. Gustafsson T, Rundqvist H, Norrbom J, Rullman E, Jansson E, Sundberg CJ. The influence of physical training on the angiopoietin and VEGF-A systems in human skeletal muscle. J Appl Physiol (1985) 2007;103(3): 1012-20.

21. Gustafsson T, Puntschart A, Kaijser L, Jansson E, Sundberg CJ. Exercise-induced expression of angiogenesis-related transcription and growth factors in human skeletal muscle. Am J Physiol Heart Circ Physiol 1999;276(2): H679-H85.

22. Gavin TP, Robinson CB, Yeager RC, England JA, Nifong LW, Hickner RC. Angiogenic growth factor response to acute systemic exercise in human skeletal muscle. J Appl Physiol (1985) 2004;96(1): 19-24.

23. Hoier B, Nordsborg N, Andersen S, Jensen L, Nybo L, Bangsbo J, et al. Pro-and anti-angiogenic factors in human skeletal muscle in response to acute exercise and training. J Physiol 2012;590(3): 595-606.

24. Brixius K, Schoenberger S, Ladage D, Knigge H, Falkowski G, Hellmich M, et al. Long-term endurance exercise decreases antiangiogenic endostatin signalling in overweight men aged 50-60 years. Br J Sports Med 2008;42(2): 126-9.

25. Hudlicka O, Brown M, Egginton S. Angiogenesis in skeletal and cardiac muscle. Physiol Rev 1992;72(2): 369-417.

26. Sundberg C, Kaijser L. Effects of graded restriction of perfusion on circulation and metabolism in the working leg; quantification of a human ischaemiamodel. Acta Physiol Scand 1992;146(1): 1-9.

27. Hudlicka O, Brown MD. Adaptation of skeletal muscle microvasculature to increased or decreased blood flow: role of shear stress, nitric oxide and vascular endothelial growth factor. J Vasc Res 2008;46(5): 504-12.

28. Gavin TP. Basal and exercise-induced regulation of skeletal muscle capillarization. Exerc Sport Sci Rev 2009;37(2): 86-92.

29. Yang HT, Prior BM, Lloyd PG, Taylor JC, Li Z, Laughlin $\mathrm{MH}$, et al. Training-induced vascular adaptations to ischemic muscle. J Physiol Pharmacol 2008;59 Suppl 7:57-70.

30. Ohno H, Shirato K, Sakurai T, Ogasawara J, Sumitani Y, Sato S, et al. Effect of exercise on HIF-1 and VEGF signaling. J Physical Fitness Sport Med 2012;1(1): 516.

31. Wickström SA, Alitalo K, Keski-Oja J. Endostatin associates with integrin $\alpha 5 \beta 1$ and caveolin-1, and activates Src via a tyrosyl phosphatase-dependent pathway in human endothelial cells. Cancer Res 2002;62(19): 5580-9. 
32. Hanai J-i, Dhanabal M, Karumanchi SA, Albanese C, Waterman M, Chan B, et al. Endostatin causes G1 arrest of endothelial cells through inhibition of cyclin D1. J Biological Chemistry 2002;277(19): 16464-9.

33. Urbich C, Reissner A, Chavakis E, Dernbach E, Haendeler J, Fleming I, et al. Dephosphorylation of endothelial nitric oxide synthase contributes to the anti-angiogenic effects of endostatin. FASEB J 2002;16(7):706-8.

34. Rullman E, Rundqvist H, Wågsäter D, Fischer H, Eriksson P, Sundberg CJ, et al. A single bout of exercise activates matrix metalloproteinase in human skeletal muscle. J Appl Physiol (1985) 2007;102(6): 2346-51.
35. Bernfield M, Götte M, Park PW, Reizes O, Fitzgerald ML, Lincecum J, et al. Functions of cell surface heparan sulfate proteoglycans. Annu Rev Biochem 1999;68(1): 729-77.

36. Ferreras M, Felbor U, Lenhard T, Olsen BR, Delaissé J-M. Generation and degradation of human endostatin proteins by various proteinases. FEBS letters 2000;486(3): 247-51.

37. Noris M, Morigi M, Donadelli R, Aiello S, Foppolo M, Todeschini M, et al. Nitric oxide synthesis by cultured endothelial cells is modulated by flow conditions. Circ Res 1995;76(4): 536-43. 